\title{
LODO DE ESGOTO ALCALINIZADO ADICIONADO DE FÓSFORO APLICADO NUM LATOSSOLO VERMELHO DISTRÓFICO DE ARAPOTI-PR ${ }^{1}$
}

\section{ALKALINE SEWAGE SLUDGE ADDED BY PHOSPORUS APPLIED ON AN OXISOL FROM ARAPOTI-PR-BRAZIL}

\author{
Luiz Carlos DA SILVA ${ }^{1}$ \\ Luiz Antonio Corrêa LUCCHESI ${ }^{2}$ \\ Henrique Soares KOEHLER ${ }^{3}$
}

\begin{abstract}
RESUMO
No estágio atual da pesquisa com lodos de esgoto seu enriquecimento com fósforo $(P)$ pode contribuir para a redução de problemas com sua destinação final e atrair produtores ao uso de quantidades adequadas destes biossólidos na agricultura. Além disso, pode reduzir custos com operações de adubação e correção de solos. Este trabalho objetivou avaliar o P extraível Mehlich-1 ( $\mathrm{HCl} 0,05 \mathrm{~mol} \mathrm{dm}^{-3}+\mathrm{H}_{2} \mathrm{SO}_{4} 0,0125 \mathrm{~mol} \mathrm{dm}^{-3}$ ) de Latossolo Vermelho Distrófico típico (LVDt), ácido, fósforo acumulado nas plantas de feijoeiro (Phaseolus vulgaris), a produtividade da cultura e a eficiência agronômica de lodo de esgoto alcalinizado adicionado de fósforo de diferentes fontes. Um lodo de esgoto alcalinizado de Curitiba foi adicionado de $0 \% \mathrm{P}, 0,436 \% \mathrm{P}, 0,872 \% \mathrm{P}$ e $1,745 \% \mathrm{P}$ oriundo de fosfato natural parcialmente acidulado Alvorada, superfosfato simples e superfosfato triplo. Quatro níveis de adição de $\mathrm{P}$ de três fontes originaram 12 tratamentos com quatro repetições. A partir dos tratamentos recomendou-se a dose de $45,85 \mathrm{~kg} \mathrm{P}$ ha ${ }^{-1}$, gerando-se como únicas causas de variação os níveis e fontes de adição de fósforo. Aplicou-se os tratamentos a $2,5 \mathrm{~kg}$ de solo em vasos cultivados com 6 plantas de feijoeiro. Lodo de esgoto alcalinizado adicionado de fósforo aumentou o $\mathrm{P}$ extraível do solo e a acumulação de $\mathrm{P}$ nas plantas bem como a produção de grãos e massa seca de feijoeiro. Tanto o fosfato natural parcialmente acidulado Alvorada quanto o superfosfato simples pode ser utilizado em mistura com lodo de esgoto alcalinizado desde que considerado o nível de $0,436 \% \mathrm{P}$.

Palavras-chave: superfosfato triplo; superfosfato simples; fosfato natural parcialmente acidulado Alvorada; produção de grãos; produção de massa seca; Phaseolus vulgaris.
\end{abstract}

ABSTRACT
At the current stage of research with sewage sludges its enrichment with phosphorus $(P)$ can contributes to the reduction of problems related to its final destination and attract farmers to the use of adequate quantities of these biosolids in agriculture. Plus, it can reduce the costs with soil fertilizers and liming operations. This work aimed to evaluate the extractable soil P Mehlich-1 $\left(\mathrm{HCl} 0,05 \mathrm{~mol} \mathrm{dm}^{-3}+\mathrm{H}_{2} \mathrm{SO}_{4} 0,0125 \mathrm{~mol} \mathrm{dm}^{-3}\right)$ of an Oxisol, plant $\mathrm{P}$ accumulation and its productivity, and the agronomic effectiveness of an alkaline sewage sludge added by phosphorus from the different sources. A sewage sludge from Curitiba, Brazil, was added by $0 \% \mathrm{P}, 0,436 \% \mathrm{P}, 0,872 \% \mathrm{P}$ e $1,745 \% \mathrm{P}$ from de partially acidulated phosphate rock Alvorada, single superphosphate and triple superphosphate. Four $\mathrm{P}$ addition levels coming from the three sources originated 12 treatments with 4 replications. From the treatments was recommended the dose of $45,85 \mathrm{~kg} \mathrm{P}^{-1}$, generating as sole causes of variation sources and levels of phosphorus addition. The treatments was applied to $2,5 \mathrm{~kg}$ of an Oxisol from Parana State Brazil, in vases cultivated with 6 common bean plants. Alkaline sewage sludge added by phosphorus increased the extractable soil P Mehlich-1 and P plant accumulation as well as the grain and dry mass production of common bean. Both the partially acidulated phosphate rock Alvorada as single superphosphate can be used in mixture with alkaline sewage sludge since is considered the level of $0,436 \% \mathrm{P}$.

Key-words: triple superphosphate; single superphosphate; partially acidulated rock phosphate Alvorada; grain production; dry mass production; Phaseolus vulgaris.

\footnotetext{
${ }^{1}$ Engenheiro Agrônomo M.Sc., bolsista da CAPES, Instituto Federal de Educação, Ciência e Tecnologia do Amazonas - Campus São Gabriel da Cachoeira. Rodovia BR 307, Km 03, s/n., IFAM, Vila Mecanização, 01, Bairro Cachoeirinha, São Gabriel da Cachoeira - AM, CEP: 69750000. E-mail: luiz_silva03@yahoo.com.br

${ }^{2}$ Universidade Federal do Paraná (UFPR), Setor de Ciências Agrárias, Rua dos Funcionários, 1540, Juvevê, CEP 80035-050, Curitiba, PR. Email: Iclucche@ufpr.br

${ }^{3}$ Universidade Federal do Paraná (UFPR), Setor de Ciências Agrárias, Rua dos Funcionários, 1540, Juvevê, CEP 80035-050, Curitiba, PR. Email: koehler@agrarias.ufpr.br
}

Scientia Agraria, Curitiba, v.11, n.5, p.393-405, Sept./Oct. 2010. 
DA SILVA, L. C. et al. Lodo de esgoto alcalinizado adicionado de...

\section{INTRODUÇÃO}

A aplicação de lodos de esgoto nos solos agrícolas pode constituir-se um método sustentável de eliminação deste passivo ambiental no ambiente urbano. Lodos de esgoto possuem matéria orgânica, alguns macro e micronutrientes, e reação alcalina (Logan \& Harrison, 1995). Tem-se observado eficiência de lodos de esgoto em alterar as propriedades químicas de solos ácidos. Trabalhos recentes com lodos de esgoto alcalinizados ou não, aplicados concomitantemente ou em mistura com fertilizantes fosfatados solúveis, têm indicado aumentos nos teores extraíveis de $\mathrm{P}$ do solo (Silva et al., 2001; Chueiri et al., 2007), na absorção de $\mathrm{P}$, produção de massa seca $\mathrm{e}$, ou, produção de grãos das culturas do feijoeiro e milho (Nascimento et al., 2004; Lourenço et al., 1996), milho (Silva et al., 2002; Simonete et al., 2003), trigo (Bar-Tal et al., 2004) e cevada (Christie et al., 2001).

Segundo Novais \& Smith (1999) as principais fontes de fósforo $(P)$ na agricultura são o superfosfato simples (SS) e superfosfato triplo (ST). Estes autores consideram os fosfatos naturais parcialmente acidulados como fontes alternativas de P. O conteúdo de P em lodos de esgoto tratados por processos alcalinizantes é baixo em relação a estes mesmos lodos in natura. Por isso, grandes quantidades destes biossólidos alcalinizados devem ser incorporadas ao solo para suprir as exigências deste nutriente pelas culturas, podendo-se, assim, elevar excessivamente o $\mathrm{pH}$ do solo e prejudicar o crescimento de plantas. Com base no exposto, a adição de $P$ em lodos de esgoto alcalinizados a partir de fontes tradicionais e, ou, alternativas pode constituir-se em procedimento sustentável e uma forma de uso de quantidades adequadas destes biossólidos na agricultura. Adicionalmente, pode-se reduzir os custos com operações de adubação fosfatada e calagem de produtores de feijão no Paraná e no Brasil que, de maneira geral, são de caráter familiar e descapitalizados. $O$ objetivo deste trabalho foi avaliar o P extraível Mehlich-1 do solo, $P$ acumulado e produtividade da cultura e a eficiência agronômica de um lodo de esgoto alcalinizado adicionado de fósforo de diferentes fontes para o cultivar IPR Uirapuru de feijoeiro (Phaseolus vulgaris L.) cultivado num Latossolo Vermelho Distrófico típico (LVDt), ácido, em casa de vegetação.

\section{MATERIAL E MÉTODOS}

Este trabalho foi realizado em casa de vegetação do Departamento de Solos e Engenharia Agrícola da Universidade Federal do Paraná, Curitiba-PR, de julho a novembro de 2006. Utilizouse TFSA (terra fina seca ao ar) proveniente dos primeiros $20 \mathrm{~cm}$ de um Latossolo Vermelho Distrófico típico (LVDt) ${ }^{1}$, textura média, coletado no município de Arapoti-PR, que apresentou os seguintes atributos iniciais: areia $=517 \mathrm{~g} \mathrm{~kg}^{-1}$; silte $=$ $158 \mathrm{~g} \mathrm{~kg}^{-1}$; argila $=325 \mathrm{~g} \mathrm{~kg}^{-1}$ (EMBRAPA, 1997); $\mathrm{pH}$ em CaCl $2=3,9 ; \mathrm{Ca}^{2+}=0,3 \mathrm{Cmol}_{\mathrm{C}} \mathrm{dm}^{-3} ; \mathrm{Mg}^{2+}=$ $0,2 \mathrm{cmol}_{\mathrm{C}} \mathrm{dm}^{-3} ; \mathrm{K}^{+}=0,12 \mathrm{cmol}_{\mathrm{C}} \mathrm{dm}^{-3} ; \mathrm{Al}^{3+}=1,9$ $\mathrm{cmol}_{\mathrm{C}} \mathrm{dm}^{-3} ; \mathrm{H}+\mathrm{Al}=11,3 \mathrm{cmol}_{\mathrm{C}} \mathrm{dm}^{-3} ; \mathrm{CTC}=11,9$ $\mathrm{cmol}_{\mathrm{c}} \mathrm{dm}^{-3} ; \mathrm{V}=5,2 \% ; \mathrm{P}=1,0 \mathrm{mg} \mathrm{dm}^{-3}$ e carbono orgânico $=23 \mathrm{~g} \mathrm{~kg}^{-1}$.

O lodo de esgoto utilizado neste trabalho foi oriundo da Estação de Tratamento de Esgotos Belém, da SANEPAR ${ }^{2}$, em São José dos Pinhais $\mathrm{PR}$, tratado pelo Processo N-Viro (Processo de Estabilização Alcalina Avançada com Subseqüente Secagem Acelerada) e passado em peneira ABNT de $4 \mathrm{~mm}$, com as seguintes características agronômicas: $\mathrm{PN}\left(\mathrm{ECaCO}_{3}\right)=93,38 \%$; PRNT = $67,54 \% ; \mathrm{pH} \mathrm{CaCl} 2=12,8 ; \mathrm{N}=4,9 \mathrm{~g} \mathrm{~kg}^{-1} ; \mathrm{P}_{2} \mathrm{O}_{5}=$ $3,47 \mathrm{~g} \mathrm{~kg}^{-1}\left(1,51 \mathrm{~g} \mathrm{P}^{-1}\right.$ tal kg-1 ou $\left.0,151 \%\right) ; \mathrm{K}_{2} \mathrm{O}=$ $1,0 \mathrm{~g} \mathrm{~kg}^{-1} ; \mathrm{S}=1,0 \mathrm{~g} \mathrm{~kg}^{-1} ;$ Ca total $=193 \mathrm{~g} \mathrm{~kg}^{-1} ; \mathrm{Mg}=$ $111 \mathrm{~g} \mathrm{~kg}^{-1}$; carbono orgânico $=31,1 \mathrm{~g} \mathrm{~kg}^{-1}$.

$\mathrm{O}$ lodo de esgoto alcalinizado (Biossólido alcalinizado $\mathrm{N}$-Viro Soil) foi adicionado de níveis $0,436 \% \quad \mathrm{P}\left(1 \% \mathrm{P}_{2} \mathrm{O}_{5}\right) ; 0,872 \% \quad \mathrm{P}\left(2 \% \mathrm{P}_{2} \mathrm{O}_{5}\right)$ e $1,745 \% \mathrm{P}\left(4 \% \mathrm{P}_{2} \mathrm{O}_{5}\right)$ provenientes de fosfato natural parcialmente acidulado Alvorada (FPA), superfosfato simples (SS) e superfosfato triplo (ST). Os teores totais de $\mathrm{P}$ e $\mathrm{P}_{2} \mathrm{O}_{5}$ nas fontes encontramse na Tabela 1.

TABELA 1 - Teores de fósforo e frações granulométricas de fosfato natural parcialmente acidulado alvorada (FPA), superfosfato simples (SS) e superfosfato triplo (ST)

\begin{tabular}{|c|c|c|c|c|c|c|c|c|c|c|c|}
\hline \multirow{3}{*}{$\mathrm{FAP}^{1}$} & \multirow[t]{3}{*}{ TTP $^{2}$} & \multirow[t]{2}{*}{$\mathrm{TTP}_{2} \mathrm{O}_{5}{ }^{3}$} & $\begin{array}{c}\mathrm{P}_{2} \mathrm{O}_{5} \mathrm{CNA}^{4} \\
+\mathrm{H}_{2} \mathrm{O}\end{array}$ & $\begin{array}{l}\mathrm{P}_{2} \mathrm{O}_{5} \\
\mathrm{H}_{2} \mathrm{O}^{5}\end{array}$ & \multicolumn{7}{|c|}{$\begin{array}{c}\text { Malhas } \\
(\mathrm{mm})\end{array}$} \\
\hline & & & & & 0,08 & 0,10 & 0,25 & 0,5 & 1 & 2 & 4 \\
\hline & & . & $-\mathrm{g} \mathrm{kg}^{-1}$ & ---- & \multicolumn{7}{|c|}{ Frações granulométricas } \\
\hline FPA & 84,3 & $193,4^{7}$ & 148,2 & 6,34 & 65,7 & 213,1 & 172,1 & 180,6 & 165,6 & 5,8 & 0 \\
\hline SS & 64,2 & $147,4^{\top}$ & 128,9 & 9,22 & 0 & 0 & 0 & 0,1 & 103,1 & 876,5 & 20,3 \\
\hline$\overline{\mathrm{ST}}$ & 195,1 & 44,7 & 441,5 & 40,04 & 0 & 0 & 0 & 0 & 2,2 & 846,7 & 150,2 \\
\hline
\end{tabular}

${ }^{1} \mathrm{FAP}$ : fonte de adição de $\mathrm{P}$ em lodo de esgoto alcalinizado; ${ }^{2} \mathrm{TTP}$ : teor total de fósforo na fonte, em $\mathrm{g} \mathrm{kg}^{-1}$, determinado pelo método do azul de molibdato, precedida de digestão nitroperclórica; ${ }^{3} \mathrm{TTP}_{2} \mathrm{O}_{5}$ : teor total de $\mathrm{P}_{2} \mathrm{O}_{5}$ na fonte, $\mathrm{g} \mathrm{kg}^{-1}$, obtido por meio de cálculo a partir do teor total de $\mathrm{P} ;{ }^{4} \mathrm{P}_{2} \mathrm{O}_{5} \mathrm{CNA}+\mathrm{H}_{2} \mathrm{O}$ : teor de $\mathrm{P}_{2} \mathrm{O}_{5}$ na fonte solúvel, $\mathrm{g} \mathrm{kg}^{-1}$, pelo método do citrato neutro de amônio + Água; ${ }^{5} \mathrm{P}_{2} \mathrm{O}_{5} \mathrm{H}_{2} \mathrm{O}$ : teor de $\mathrm{P}_{2} \mathrm{O}_{5}$ solúvel em água, $\mathrm{g} \mathrm{kg}^{-1} ;{ }^{6} \mathrm{~g} \mathrm{~kg}{ }^{-1}$ : quantidade da fração granulométrica do fertilizante retida na malha, em g kg ${ }^{-1}$; Teores abaixo da legislação, provavelmente, em função de amostragem não representativa de lote de fertilizante efetuada por funcionários de empresas fornecedoras

\footnotetext{
${ }^{1}$ Solo coletado sob Floresta subtropical perenifólia em sucessão secundária, nunca cultivado.

2 Companhia de Saneamento do Estado do Paraná.
} 
DA SILVA, L. C. et al. Lodo de esgoto alcalinizado adicionado de ...

Para o estabelecimento de tratamentos recomendou-se uma dose de $45,85 \mathrm{~kg} \mathrm{ha}^{-1}$ de $\mathrm{P}$ (105 kg $\mathrm{P}_{2} \mathrm{O}_{5} \mathrm{ha}^{-1}=23 \mathrm{mg} \mathrm{dm}^{-3}$ de $\mathrm{P}$ ) a partir de cada tratamento (CQFS RS/SC, 2004). Quando esta dose foi recomendada a partir do nível de adição $0,436 \% \mathrm{P}$, independentemente da fonte, os cálculos de quantidades de lodo + fontes de $\mathrm{P}$ forneceram uma dose máxima de $10500 \mathrm{~kg} \mathrm{ha}^{-1} \mathrm{de}$ mistura de adição de $\mathrm{P}$ em lodo de esgoto alcalinizado. Assim, tomou-se a dose de $10500 \mathrm{~kg}$ $\mathrm{ha}^{-1}$ de lodo de esgoto alcalinizado sem adição de fósforo como testemunhas específicas para cada fonte de adição (Tabela 2). Obteve-se, assim, 4 níveis e 3 fontes de adição de $P$, totalizando-se 12 tratamentos com 4 repetições, sendo níveis e fontes de $\mathrm{P}$ as únicas causas de variação. O delineamento experimental foi inteiramente casualizado em arranjo fatorial 4 por 3 .

TABELA 2 - Doses totais, por vaso, de lodo de esgoto alcalinizado adicionado de fósforo, quantidade de fontes fósforo e dose pura de lodo nas misturas para estabelecimento de tratamentos

\begin{tabular}{|c|c|c|c|c|c|c|}
\hline \multirow{2}{*}{$\begin{array}{l}\text { Tratamentos } \\
\text { (T) }\end{array}$} & \multirow{2}{*}{ FAP $^{1}$} & \multirow{2}{*}{$\begin{array}{l}\mathrm{NAP}^{2} \\
(\%)\end{array}$} & $\mathrm{DT}^{3}$ & $\mathrm{QL}^{4}$ & $\mathrm{QF}^{5}$ & $\mathrm{DP}^{6}$ \\
\hline & & & \multicolumn{4}{|c|}{ 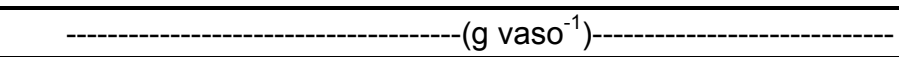 } \\
\hline $\mathrm{T} 1$ & FPA & 0,000 & 13,125 & 13,125 & 0,000 & 0,000 \\
\hline $\mathrm{T} 2$ & FPA & 0,436 & 13,125 & 12,445 & 0,680 & 0,057 \\
\hline T3 & FPA & 0,872 & 6,563 & 5,883 & 0,680 & 0,057 \\
\hline $\mathrm{T} 4$ & FPA & 1,745 & 3,281 & 2,612 & 0,680 & 0,057 \\
\hline T5 & $S S^{8}$ & 0,000 & 13,125 & 13,125 & 0,000 & 0,000 \\
\hline T6 & SS & 0,436 & 13,125 & 12,235 & 0,890 & 0,057 \\
\hline $\mathrm{T} 7$ & SS & 0,872 & 6,563 & 5,673 & 0,890 & 0,057 \\
\hline T8 & SS & 1,745 & 3,281 & 2,391 & 0,890 & 0,057 \\
\hline T9 & $\mathrm{ST}^{9}$ & 0,000 & 13,125 & 13,125 & 0,000 & 0,000 \\
\hline $\mathrm{T} 10$ & ST & 0,436 & 13,125 & 12,831 & 0,294 & 0,057 \\
\hline T11 & ST & 0,872 & 6,563 & 6,269 & 0,294 & 0,057 \\
\hline $\mathrm{T} 12$ & ST & 1,745 & 3,281 & 2,987 & 0,294 & 0,057 \\
\hline
\end{tabular}

${ }^{1}$ FAP: fonte de adição de $\mathrm{P}$ em lodo de esgoto alcalinizado; ${ }^{2} \mathrm{NAP}$ : nível de adição de $\mathrm{P}$ em lodo de esgoto alcalinizado, em percentagem; ${ }^{3} \mathrm{DT}$ : dose total por vaso de lodo de esgoto alcalinizado adicionado de $\mathrm{P}$ (considerada a densidade do solo $=$ $1,000 \mathrm{~g} \mathrm{~cm}^{-3}$ ); ${ }^{4} \mathrm{QL}$ : quantidade de lodo de esgoto alcalinizado puro na mistura de adição de $\mathrm{P}$ (considerada a densidade do solo $\left.=1,000 \mathrm{~g} \mathrm{~cm}^{-3}\right) ;{ }^{5} \mathrm{QF}$ : quantidade da fonte de $\mathrm{P}$ na mistura de adição para suprir a dose-teste de $45,851 \mathrm{~kg} \mathrm{P}^{-1} \mathrm{de} P$ $\left(105 \mathrm{~kg} \mathrm{P}_{2} \mathrm{O}_{5} \mathrm{ha}^{-1}\right.$ ) recomendada a partir de cada tratamento (considerada a densidade do solo $\left.=1,000 \mathrm{~g} \mathrm{~cm}^{-3}\right) ;{ }^{6} \mathrm{DP}:$ dose de $\mathrm{P}$ recomendada para $1 \mathrm{ha}^{-1}$ (2000000 kg médios de solo da camada arável), equivalente a $105 \mathrm{~kg} \mathrm{ha}^{-1}$ de $\mathrm{P}_{2} \mathrm{O}_{5}$ (considerada a densidade do solo $=1,000 \mathrm{~g} \mathrm{~cm}^{-3}$ ); ${ }^{7} \mathrm{FPA}$ : fosfato natural parcialmente acidulado Alvorada; ${ }^{8} \mathrm{SS}$ : superfosfato simples; ${ }^{9} \mathrm{ST}$ : superfosfato triplo.

As doses por hectare ${ }^{3}$ da mistura de lodo de esgoto alcalinizado + fontes de $P$ para suprir $45,85 \mathrm{~kg} \mathrm{ha}^{-1}$ de $P$ foram calculadas para vasos de $3 \mathrm{dm}^{3}$ contendo $2,5 \mathrm{~kg}$ de TFSA. Em seguida foram pesadas em balança de precisão e misturadas homogeneamente (Tabela 2). Vinte e quatro horas após seu preparo os tratamentos foram aplicados e misturados de forma homogênea no solo, que foi regado até a capacidade de retenção de água. Sementes da cultivar IPR Uirapuru de feijão (Phaseolus vulgaris L.), de hábito indeterminado, foram postas para germinar nos vasos. Doze dias após a semeadura procedeu-se ao desbaste deixando-se seis plantas por vaso. Adubações nitrogenada e potássica (nitrato de potássio) foram feitas de acordo com a análise da TFSA e com base na recomendação de adubação para o feijoeiro preconizada para os estados do Rio Grande do Sul e Santa Catarina (CQFS RS/SC, 2004) com base no volume dos vasos. Os adubos foram adicionados em doses correspondentes a $30 \mathrm{~kg} \mathrm{ha}^{-1}$ de $\mathrm{N}$ e 60 $\mathrm{kg} \mathrm{ha}^{-1}$ de $\mathrm{K}_{2} \mathrm{O}$ em cobertura nos vasos, na forma de nitrato de potássio $\left(\mathrm{KNO}_{3}\right)$, aos 13 dias após a germinação. A colheita foi feita cortando-se as plantas com tesoura de poda à altura de $0,5 \mathrm{~cm}$ do nível do solo, aos 95 dias da semeadura (estádio R9). Todo o material colhido ${ }^{4}$ foi seco em estufa de circulação forçada a $65^{\circ} \mathrm{C}$ até peso constante. A produção de massa seca total da parte aérea das plantas de feijoeiro (MSTPA), em g vaso ${ }^{-1}$, foi obtida pesando-se talo + hastes + folhas + pedicelos + vagens com grãos em balança de precisão. A produção de grãos, em g vaso ${ }^{-1}$, foi obtida pesandoos separadamente após trilhagem manual de vagens. Após a colheita foram coletadas amostras compostas de solo (de 6 amostras simples) para análise do $\mathrm{P}$ extraível Mehlich-1.

\footnotetext{
31,0 ha $=2 \times 10^{6} \mathrm{~kg}$ médios de solo da camada arável. A densidade do solo, de $1,030 \mathrm{~g} \mathrm{~cm}^{-3}$ (Embrapa, 1997) foi considerada $1,000 \mathrm{~g} \mathrm{~cm}^{-3}$ para fins de recomendação da dose teste de fósforo a partir de cada tratamento.

${ }^{4}$ Todo o material senescente que caiu das parcelas experimentais anteriormente à colheita foi recolhido para se somar ao material posteriormente colhido.
} 
DA SILVA, L. C. et al. Lodo de esgoto alcalinizado adicionado de...

A massa seca total da parte aérea foi submetida à digestão nitroperclórica e o extrato utilizado para a determinação de $\mathrm{P}$ pelo método do azul de fosfomolibdato (Pavan et al., 1992). Os resultados de fósforo acumulado pelas plantas foram expressos em g vaso-1.

As variáveis analisadas foram submetidas ao teste de Bartlett para avaliar a homogeneidade de variâncias. As comparações de médias foram feitas pelo teste de Tukey $(P<0,05)$ no software MStatc (Michigan State University). Ajustes de curva de tendência foram gerados a fim de se constatar correlações entre as variáveis avaliadas. Foram determinados índices de eficiência agronômica (IEA) para as melhores fontes de adição de fósforo em lodo de esgoto alcalinizado de acordo com a equação 1 (Chien et al., 1990):

$\operatorname{IEA}(\%)=Y_{\mathrm{n} \%} / Y_{2} \times 100$

Equação 1

sendo que: IEA (\%): índice de eficiência agronômica, em percentagem; Yn\%: Produção de massa seca total da parte aérea de feijoeiro obtida com os tratamentos referentes aos níveis de adição de $0,436 \%$, ou $0,872 \%$ ou $1,745 \%$ de $\mathrm{P}$ a partir de fontes de adição testadas (FPA e SS); $Y_{2}$ : Produção de massa seca total da parte aérea de feijoeiro obtida com os tratamentos referentes aos níveis de adição de $0,436 \%$, ou $0,872 \%$ ou $1,745 \%$ de $P$ da fonte de adição ST, tomada como fonte de referência de adição de $\mathrm{P}$ em lodo de esgoto alcalinizado.

\section{RESULTADOS E DISCUSSÃO}

Houve significância na interação nível e fonte de adição de $\mathrm{P}$ em lodo de esgoto alcalinizado para o $\mathrm{P}$ extraível Mehlich-1 das amostras de solo $(F<0,01)$. Aumentos nos teores extraíveis do nutriente foram verificados para todos os tratamentos em relação ao teor original do solo. $\mathrm{O}$ tratamento referente à testemunha (nível $0 \% \mathrm{P}$ ) dobrou o teor extraível de $\mathrm{P}$ em relação ao teor original do solo. Cerca de $50 \%$ do $P$ orgânico pode ser liberado e, consequentemente, disponibilizado às plantas já no $1^{\circ}$ ano.
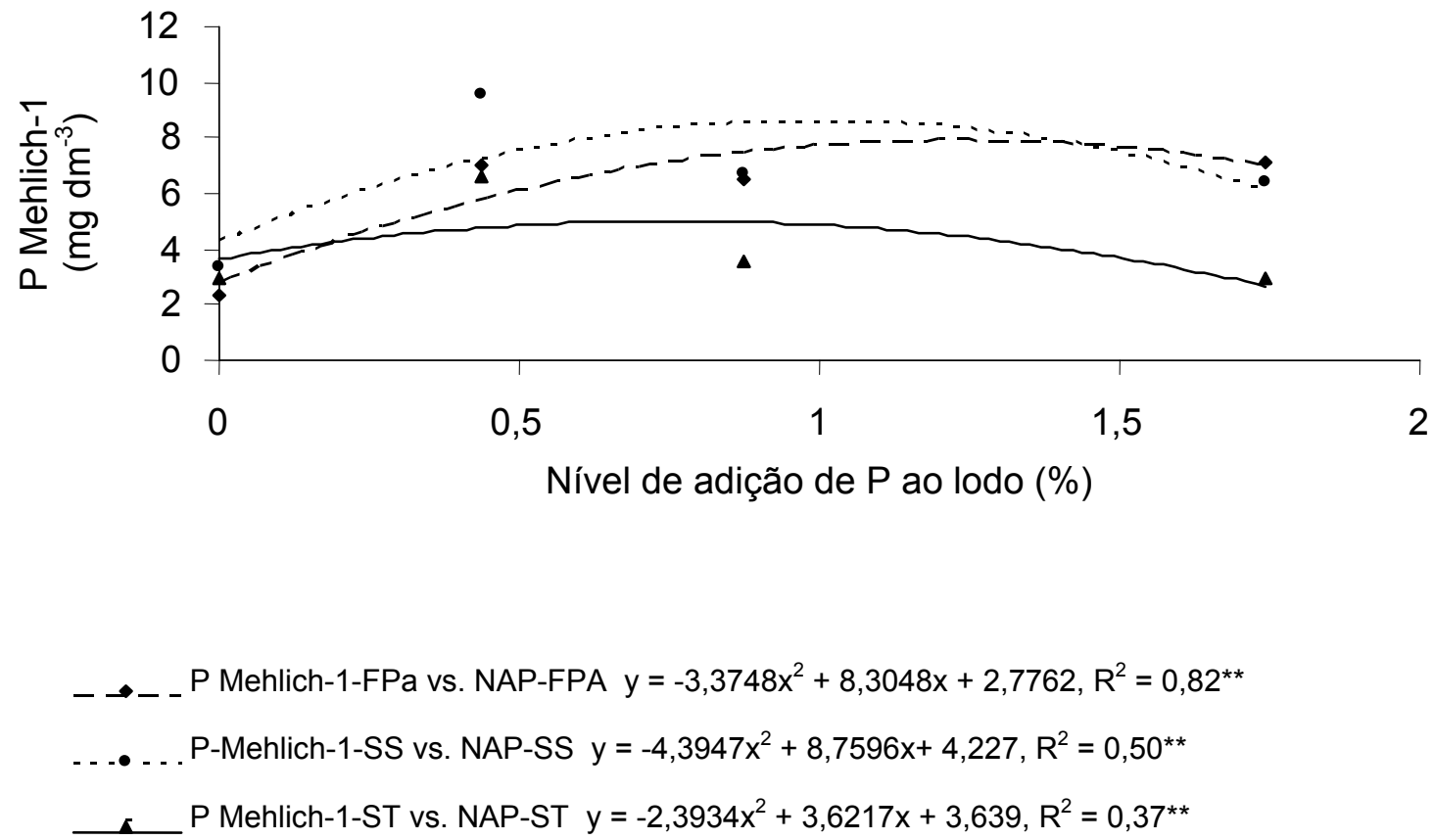

FIGURA 1 - Fósforo extraível Mehlich-1 em Latossolo Vermelho Distrófico em função do nível de adição de fósforo em lodo de esgoto alcalinizado a partir de fosfato natural parcialmente acidulado Alvorada ( $P$ Mehlich-1 vs. NAP-FPA), superfosfato simples (P Mehlich-1 vs. NAP-SS) e superfosfato triplo ( $P$ Mehlich-1 vs. NAP-ST) (F a $\mathrm{P}<0,01)$ 
DA SILVA, L. C. et al. Lodo de esgoto alcalinizado adicionado de ...

O nível de $0,436 \% \mathrm{P}$ a partir de SS mostrou-se estatisticamente superior em relação às demais fontes de adição e à testemunha $(0 \% \mathrm{P})$, proporcionando um teor extraível médio de $9,6 \mathrm{mg}$ $\mathrm{dm}^{-3}$ de $\mathrm{P}$ e aumento de $8,6 \mathrm{mg} \mathrm{dm}^{-3}$ ou cerca de $41,7 \%$ de recuperação em relação à dose total aplicada $\left(45,85 \mathrm{~kg} \mathrm{ha}^{-1}=23 \mathrm{mg} \mathrm{dm}^{-3}\right)$. Em seguida estiveram os níveis de adição $0,436 \% \mathrm{P}(7,025 \mathrm{mg}$ $\left.\mathrm{dm}^{-3}\right), 0,872 \% \mathrm{P}\left(6,500 \mathrm{mg} \mathrm{dm}^{-3}\right)$ e $1,745 \% \mathrm{P}(7,150$ $\mathrm{mg} \mathrm{dm}^{-3}$ ) a partir do FPA que proporcionaram, respectivamente, $30,5 \%, 28,2 \%$ e $31 \%$ de recuperação. Para o nível $0,436 \% \mathrm{P}$ a partir do superfosfato triplo foram verificados $6,6 \mathrm{mg} \mathrm{dm}^{-3}$ de $\mathrm{P}$, o melhor valor de $\mathrm{P}$ extraível com a fonte ST equivalente a $5,6 \mathrm{mg} \mathrm{dm}^{-3}$ de $P$ de aumento em relação ao teor original e $3,65 \mathrm{mg} \mathrm{dm}^{-3}$ de $P$ em relação à testemunha específica para esta fonte. $A$ percentagem de recuperação de $P$ do solo foi de cerca de $28,6 \%$ de recuperação do fósforo a partir da fonte ST. Foram observadas correlações quadráticas para o $\mathrm{P}$ extraível em função de níveis de adição de $\mathrm{P}$ a partir de FPA e SS, o que não ocorreu estes níveis de adição a partir de ST (Figura 1). devidos:

Estes resultados são possivelmente

a) à maior quantidade de lodo de esgoto alcalinizado puro no tratamento com $0,436 \% \mathrm{P}$ proveniente do SS (Tabela 2), que pode ter sido mineralizada e, com isso, solubilizado parte do $P$ orgânico total nela contido e aumentando o teor extraível de $\mathrm{P}$ em comparação aos demais tratamentos.

b) Ao teor solúvel de $\mathrm{P}$ presente no $\mathrm{SS}$ (Tabela 1) a despeito de seu teor total mínimo estar abaixo do exigido pela legislação. Segundo a CQFS-SC/RS (2004) esta fonte de P deve apresentar, no mínimo, $16 \%$ de $\mathrm{P}$ solúvel em água. Sua forma granulada deve permitir menor contato com o solo e, consequentemente, menor fixação de $\mathrm{P}$ no solo. As quantidades maiores de SS podem ter influenciado na distribuição do fertilizante no volume do solo, resultando em teores de $\mathrm{P}$ disponível mais elevado nas análises.

c) ao teor solúvel de $\mathrm{P}$ presente no FPA e à sua granulometria (Tabela 1) que, sob as condições ácidas iniciais de solo, pode ter sua parte não-acidulada (fosforita alvorada) dissolvida com consequente liberação de parte do $\mathrm{P}$ total para a solução do solo.

Os menores níveis de adição deveriam exercer efeito contrário sobre os teores extraíveis de $\mathrm{P}$ no solo por possuirem maiores doses de lodo de esgoto alcalinizado puro e alto teor de cálcio nas misturas. Os materiais alcalinos $(\mathrm{CaO}, \mathrm{CaOH}$, $\mathrm{CaCO}_{3}$ e $\mathrm{MgCO}_{3}$ ) comumente utilizados no tratamento de biossólidos de esgoto possuem alto teor total de $\mathrm{Ca}$ e poderiam levar o $\mathrm{P}$ oriundo de fontes mais solúveis, como o SS, à precipitação. Este fato não ocorreu, possivelmente, devido ao pouco tempo de contato das fontes de $\mathrm{P}$ com o lodo (24 horas) bem como à dispersão dos componentes da mistura no solo no momento da aplicação. Devido a esse teor de cálcio, menor concentração de fósforo extraível deveria ser encontrada para os tratamentos referentes aos níveis $0,436 \%$ de adição de P. No entanto, mesmo a partir de FPA e ST, observaram-se maiores valores de fósforo extraível no solo para este nível de adição (Tabela 3). Chueiri et al. (2007) aplicaram doses crescentes de lodo de esgoto alcalinizado num Latossolo Vermelho Distrófico e uma adubação mineral fosfatada cuja dose para a cultura do trigo foi semelhante à utilizada neste trabalho. A despeito da alta concentração inicial do nutriente apontada pela análise, verificaram aumento linear de $P$ extraível Mehlich-1 no solo, fato que atribuíram aos altos valores de $\mathrm{pH}$ proporcionados pelo lodo incubado com o solo durante 20 dias, o que pode ter solubilizado compostos de $\mathrm{P}$ e aumentado os valores extraíveis de $\mathrm{P}$ do solo.

TABELA 3 - Comparação de médias de P extraível Mehlich-1 em função de fontes de adição de $\mathrm{P}$ em lodo de esgoto alcalinizado (Teste F a 1\%)

\begin{tabular}{|c|c|c|c|c|}
\hline \multirow{2}{*}{$\mathrm{FAP}^{2}$} & \multicolumn{4}{|c|}{$\operatorname{NAP}^{1}(\%)$} \\
\hline & 0 & 0,436 & 0,872 & 1,745 \\
\hline \multicolumn{5}{|c|}{ - } \\
\hline $\mathrm{FPA}^{3}$ & $2,300 \mathrm{~b}$ & $7,025 \mathrm{~b}$ & $6,500 \mathrm{a}$ & $7,150 \mathrm{a}$ \\
\hline$S S^{4}$ & 3,325 a & $9,600 \mathrm{a}$ & $6,725 a$ & $6,425 b$ \\
\hline $\mathrm{ST}^{5}$ & $2,950 a b$ & $6,600 \mathrm{~b}$ & $3,600 \mathrm{~b}$ & $2,900 \mathrm{c}$ \\
\hline CV (\%) & 5,35 & & & \\
\hline DMS & 3,54 & & & \\
\hline
\end{tabular}

Médias seguidas de mesma letra na vertical não diferem estatisticamente pelo teste de Tukey ao nível de $95 \%$ de probabilidade.

${ }^{1} \mathrm{NAP}(\%)$ = nível de adição de lodo de esgoto alcalinizado com fósforo, em percentagem; ${ }^{2} \mathrm{FAP}$ : fonte de adição de $\mathrm{P}$ em lodo de esgoto alcalinizado; ${ }^{3}$ FPA: fosfato natural parcialmente acidulado alvorada; ${ }^{4} \mathrm{SS}$ : Superfosfato simples; ${ }^{5} \mathrm{ST}$ : Superfosfato triplo.

Scientia Agraria, Curitiba, v.11, n.5, p.393-405, Sept./Oct. 2010. 
DA SILVA, L. C. et al. Lodo de esgoto alcalinizado adicionado de...

Em relação ao fósforo acumulado na massa seca de feijoeiro $(F<0,01)$ foi observada significância isolada para o fator nível de adição de $P$. Todos os níveis de adição aumentaram o acúmulo médio de $P$, mostrando-se iguais entre si e superiores às médias observadas para a testemunha (níveis $0 \% \mathrm{P}$ ). A acumulação de $\mathrm{P}$ aumentou a partir da testemunha e apresentou tendência à diminuição com o aumento de níveis de $\mathrm{P}$ adicionados, o que é corroborado pela estreita correlação quadrática e negativa verificada entre o $\mathrm{P}$ acumulado e níveis de adição (Figura 2). Chueiri et al. (2007) aplicaram doses crescentes de lodo de esgoto alcalinizado e uma adubação fosfatada semelhante a utilizada neste trabalho e não verificaram alterações nos teores de $P$. Saliente-se que, no presente trabalho, as quantidades de lodo alcalinizado puro nas misturas são diminuídas à medida em que aumentam os níveis de adição de fósforo (Tabela 2), sendo a dose máxima do biossólido de aproximadamente $10 \mathrm{Mg} \mathrm{ha}^{-1}$ nos menores níveis de adição. Este fato, aliado aos aumentos do $\mathrm{P}$ extraível no solo, verificados a partir dos menores níveis de adição $(0,436 \% \mathrm{P})$, conduz à conjectura de que lodos de esgoto de reação alcalina no solo $(\mathrm{pH}>12,0)$, ao aumentar o $\mathrm{P}$ extraível do solo, ocasiona consequentemente, valores numericamente maiores de $P$ acumulado a partir deste nível de adição. As concentrações de $P$ acumulado na massa seca de feijoeiro estiveram entre 8 e $11,2 \mathrm{~g} \mathrm{~kg}^{-1}$ de $\mathrm{P}$, um valor extremamente alto de acumulação do nutriente face ao que se observa na literatura em geral (1 a $5 \mathrm{~g} \mathrm{~kg}^{-1}$ de $\mathrm{P}$ ). Entretanto, há que se ressaltar o fato de que, plantas de feijoeiro desenvolvidas em casa de vegetação podem acumular mais $P$ no tecido quando comparadas com plantas desenvolvidas no campo uma vez que as raízes podem ter maior contato com o nutriente no solo dos vasos. Além disso, podem existir diferenças entre genótipos de feijoeiro quanto a absorção e potencial de acumulação de $\mathrm{P}$ nas plantas, fato este constatado por Fageria (1998) que investigou diferentes genótipos de feijoeiro. Este autor observou que certos cultivares de feijoeiro podem não responder a altas acumulações de $P$ uma vez que absorvem altas quantidades do nutriente do solo sem, porém, produzir maior quantidade de biomassa. A cultivar utilizada neste trabalho, provavelmente, pertence a um desses grupos.

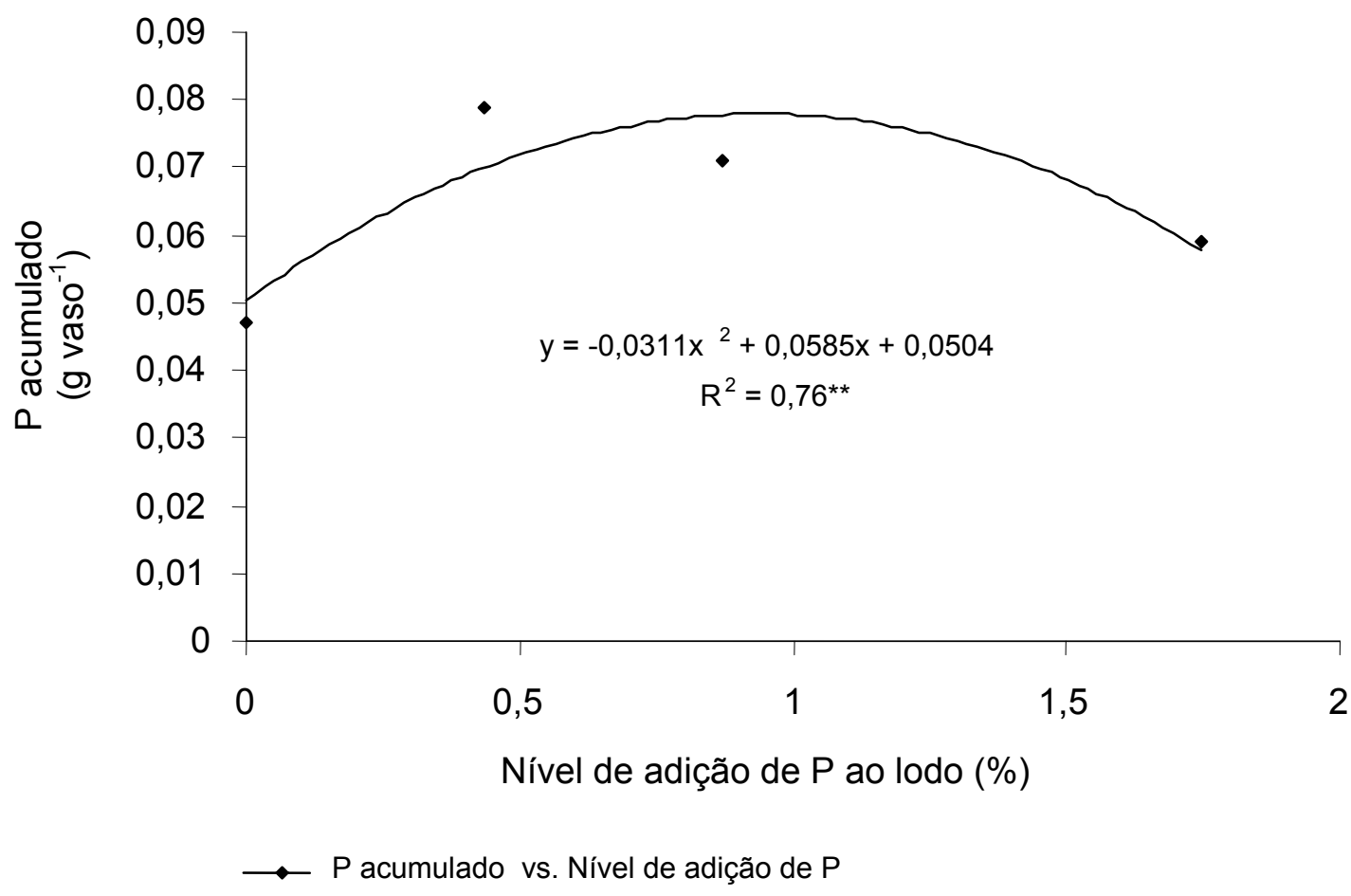

FIGURA 2 - Curva de tendência de fósforo acumulado médio em função do nível de adição de $P$ em lodo de esgoto alcalinizado a partir de fosfato natural parcialmente acidulado Alvorada (FPA), superfosfato simples (SS) e superfosfato triplo (ST) (Fator nível de adição de $P$ isoladamente significativo para $\mathrm{F}$ a $\mathrm{P}<0,01$ ) 
DA SILVA, L. C. et al. Lodo de esgoto alcalinizado adicionado de ...

A elevada acumulação de $P$ pelas plantas de feijoeiro ainda pode ser explicada pela relação Ca:Mg trocável inicial do solo $(1,5: 1,0)$, que esteve próxima das acumulações consideradas propícias ao equilíbrio entre nutrientes e à maior absorção de P (2:1 e 3:1) de acordo com Muñoz Hernandez \& Silveira (1998). Cabe salientar que, mesmo com a mudança na relação Ca:Mg trocável no solo, observou-se uma manutenção de sua proporção em função da relação $\mathrm{Ca}: \mathrm{Mg}$ total destes nutrientes presentes no lodo (cerca de 1,7:1) que, ao dissolver-se no solo, pode ter liberado $\mathrm{Ca} \mathrm{e}$, principalmente, Mg para a solução do solo. Está bem consolidado na literatura o fato de que a absorção de $\mathrm{P}$ é máxima quando $\mathrm{O} \mathrm{Mg}$ está disponível em concentrações adequadas na superfície das raízes, pois, este nutriente atua como um carregador de $\mathrm{P}$ na planta. Outros nutrientes, tais como $\mathrm{N}, \mathrm{Ca}, \mathrm{Mg}, \mathrm{S}, \mathrm{Cu}$ e $\mathrm{Zn}$, além do $\mathrm{P}$ presentes tanto no lodo de esgoto alcalinizado puro quanto nas fontes de $\mathrm{P}$ das misturas de adição podem ter corroborado com o equilíbrio de nutrientes no solo e, consequentemente, com a alta acumulação de $P$ na massa seca total da parte aérea de feijoeiro.

Também houve significância estatística na interação nível e fonte de adição de $\mathrm{P}$ em lodo de esgoto alcalinizado para a variável produção de grãos $(F<0,01)$. Os níveis $0,436 \%, 0,872 \%$ e $1,745 \%$ de adição de $P$ a partir de FPA aumentaram a produção de grãos em até $46 \%$. Para estes mesmos níveis de adição a partir do SS foram verificados aumentos de até $41 \%$ de grãos produzidos. Estes resultados são confirmados pelas altas correlações quadráticas verificadas para produção de grãos em função de níveis de adição de $\mathrm{P}$ a partir de FPA e SS (Figura 3). Dessa forma, conjectura-se que, doses intermediárias de lodo de esgoto alcalinizado (cerca de $10 \mathrm{Mg} \mathrm{ha}^{-1}$ ) podem ser utilizadas em misturas com $P$, não sofrendo as plantas detrimento na disponibilidade de $\mathrm{P}$ pelo extrator Mehlich-1 com consequente redução da produção de grãos (Figura 4). Esta verificação pode ser corroborada, adicionalmente, pela alta acumulação de $\mathrm{P}$ verificada para todos os tratamentos, exceto para as testemunhas (Figura 2). Alguns trabalhos de metodologia relativamente semelhantes são encontrados na literatura cujos resultados podem corroborar com os aqui encontrados. Dentre estes está o de Christie et al. (2001), que aplicaram doses crescentes de 0,7, 3,4, 5,1 e 6,8 vezes maiores que a dose máxima de biossólido de esgoto alcalinizado utilizada neste trabalho e, comparando sua capacidade fertilizante com um fertilizante fosfatado mineral, os autores verificaram que a produção média de grãos e peso de mil grãos de cevada obtidas com o biossólido foi maior que a obtida com a fertilização mineral para dois anos de observação. Resultado similar também foi encontrado por Bar-Tal et al. (2004), que utilizaram doses altas e crescentes de biossólido de esgoto ( 3,6 e 12 vezes maiores que a dose máxima do presente trabalho) e verificaram aumentos lineares na produção de grãos de trigo num período

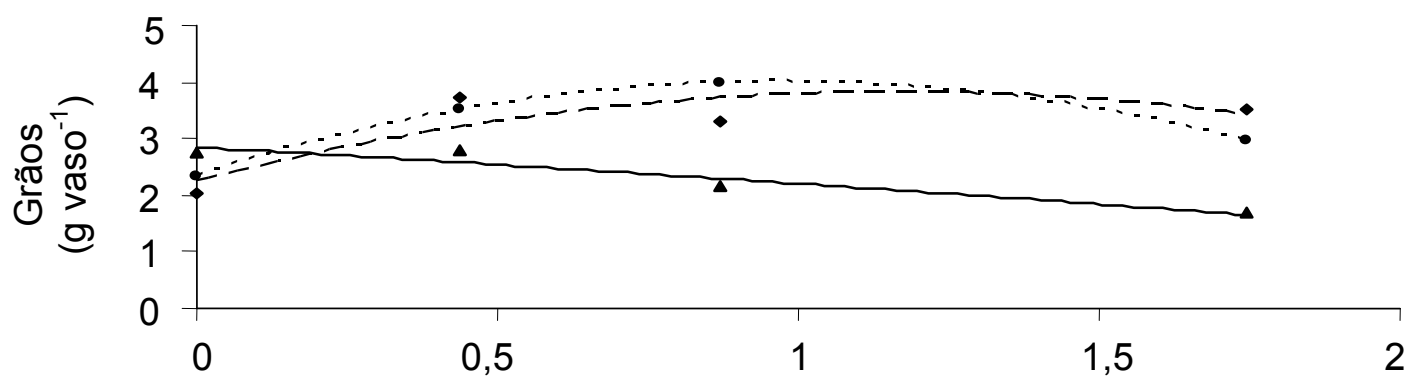

Nível de adição de P ao lodo (\%)

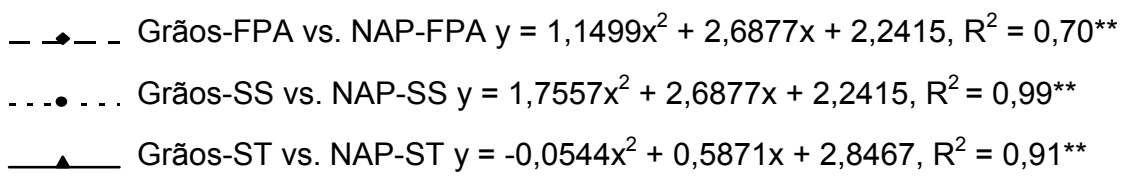

FIGURA 3 - Curvas de tendência de produção de grãos de feijoeiro em função do nível de adição de fósforo em lodo de esgoto alcalinizado a partir de fosfato natural parcialmente acidulado (Grãos-FPA vs. NAPFPA), superfosfato simples (Grãos-SS vs. NAP-SS) e superfosfato triplo (Grãos-ST vs. NAP-ST) (F a $P<0,01)$ 
DA SILVA, L. C. et al. Lodo de esgoto alcalinizado adicionado de...

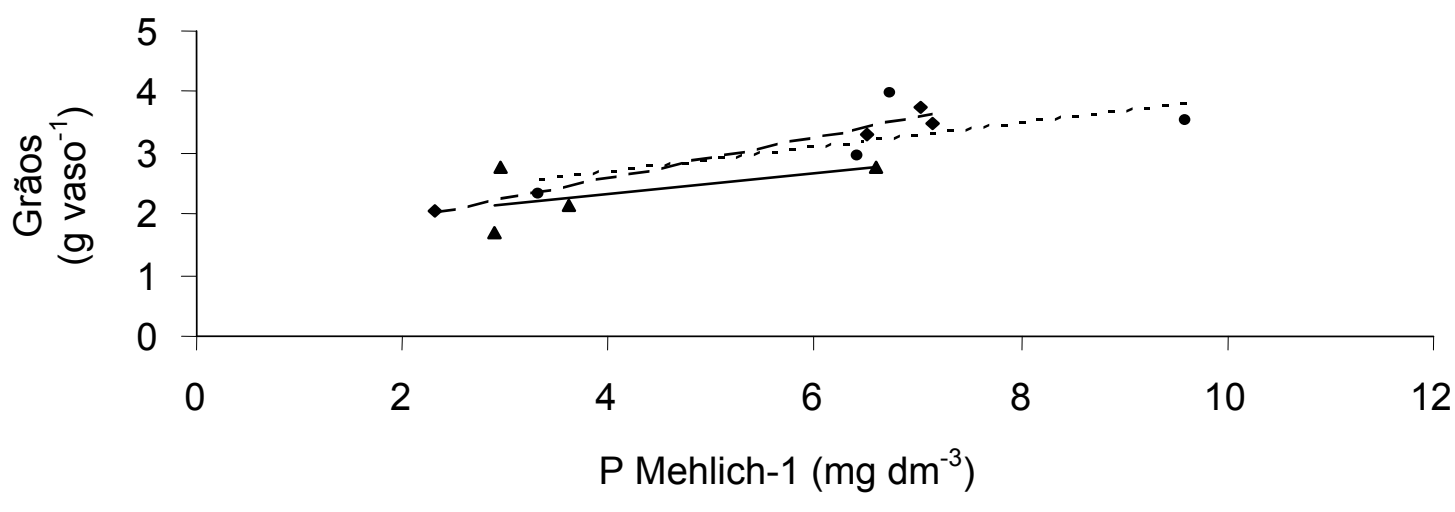

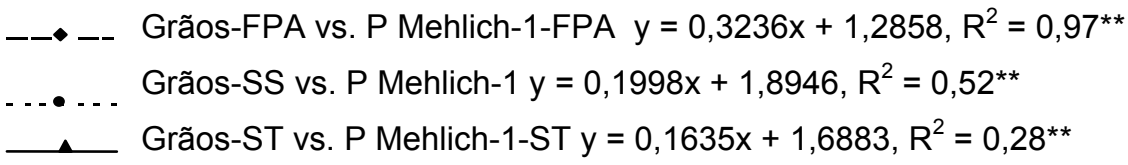

FIGURA 4 - Curvas de tendência de produção de grãos de feijoeiro em função de fósforo extraível Mehlich-1 proporcionado pelo nível de adição de fósforo em lodo de esgoto alcalinizado a partir de fosfato natural parcialmente acidulado (Grãos-FPA vs. P Mehlich-1-FPA), superfosfato simples (GrãosSS vs. P Mehlich-1-SS) e superfosfato triplo (Grãos-ST vs. P Mehlich-1-ST) (F a P<0,01)

O nível de $0,436 \% \mathrm{P}$ de ST proporcionou uma produção de grãos estatisticamente igual à testemunha e, ratificando tais resultados, alta correlação linear negativa também foi verificada para grãos produzidos em função de níveis de adição de $\mathrm{P}$ a partir desta fonte (Figura 4). Numericamente, o ST proporcionou as menores produções de grãos quando comparado às demais fontes de adição de $\mathrm{P}$ em lodo de esgoto alcalinizado (Tabela 4). O fato pode-se dever à alta concentração de Al tóxico, a acidez excessiva e a baixa disponibilidade de $\mathrm{P}$ e outros macro e micronutrientes no solo inicialmente. As plantas podem ter acessado o $\mathrm{P}$ e aos demais nutrientes presentes no lodo, porém, em relação ao $\mathrm{P}$ do fertilizante, por ser de granulometria mais grosseira, os grânulos podem não ter sido distribuidos homogeneamente no volume de solo não permitindo o acesso das plantas ao nutriente para a obtenção de produção equivalente às demais fontes. Trabalhos de muitas décadas mostram majoritariamente o ST mais eficiente ou, no mínimo, equivalente a fosfatos parcialmente acidulados e SS como fonte de $\mathrm{P}$ para as mais diversas culturas agrícolas.

TABELA 4 - Comparação de médias de produção de grãos de feijoeiro em função de fontes de adição de $P$ em lodo de esgoto alcalinizado ( $\mathrm{F}$ a $\mathrm{P}<0,01)$

\begin{tabular}{|c|c|c|c|c|}
\hline \multicolumn{5}{|c|}{$\operatorname{NAP}^{1}(\%)$} \\
\hline $\mathrm{FAP}^{2}$ & 0 & 0,436 & 0,872 & 1,745 \\
\hline \multicolumn{5}{|c|}{ 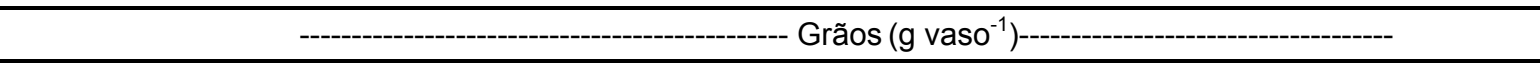 } \\
\hline FPA $^{3}$ & $2,037 \mathrm{a}$ & $3,740 \mathrm{a}$ & $3,302 \mathrm{a}$ & 3,498 a \\
\hline$S S^{4}$ & $2,335 a$ & 3,525 a & $3,968 \mathrm{a}$ & $2,960 \mathrm{a}$ \\
\hline $\mathrm{ST}^{5}$ & 2,770 a & 2,785 a & $2,140 \mathrm{~b}$ & $1,682 b$ \\
\hline CV (\%) & 21,11 & & & \\
\hline DMS & 1,03 & & & \\
\hline $\begin{array}{l}\text { Médias se } \\
\text { probabilida } \\
{ }^{1} \mathrm{NAP}(\%) \\
\text { esgoto alc } \\
\text { Superfosfa }\end{array}$ & $\begin{array}{l}\text { mesma } \\
\text { adição de } \\
\text { om fósfo }\end{array}$ & $\begin{array}{l}\text { ă difer } \\
\text { linizado }\end{array}$ & $\begin{array}{l}\text { pelo te } \\
\text { entagem } \\
\text { Alvora }\end{array}$ & $\begin{array}{l}\text { o nível de } 5 \% \text { de } \\
\text { e adição de lodo de } \\
\text { sfato simples; }{ }^{5} \mathrm{ST} \text { : }\end{array}$ \\
\hline
\end{tabular}


DA SILVA, L. C. et al. Lodo de esgoto alcalinizado adicionado de ...

Saliente-se ainda que o nível $0,436 \% \mathrm{P}$, por possuir maiores quantidades de lodo de esgoto alcalinizado puro, pode ter fornecido outros macro e micronutrientes às plantas. Eram nítidos os efeitos negativos da acidez do solo sobre todas as plantas em todos os tratamentos. Este fato ocorreu pela baixa disponibilidade de macronutrientes (Tabela 2) e micronutrientes e, consequentemente, por um desequilíbrio geral de nutrientes no solo. Prováveis aumentos na disponibilidade destes nutrientes no solo, além de relacionar-se com a superação dos sintomas iniciais de carência apresentados por todas as plantas em todos os tratamentos, podem ter corroborado com a maior produção de grãos de feijoeiro a partir daquele tratamento $(0,436 \% \mathrm{P})$.

Também foi significativa a interação nível e fonte de adição de $\mathrm{P}$ em lodo de esgoto alcalinizado para a produção de massa seca total da parte aérea de feijoeiro $(F<0,01)$. De maneira semelhante à produção de grãos, os níveis de adição $0,436 \% \mathrm{P}$ $0,872 \% \mathrm{P}$ e $1,745 \% \mathrm{P}$ a partir do FPA e SS aumentaram a produção de massa seca de feijoeiro, exceto para a fonte ST, com a qual se observou uma redução linear na produção à medida em que aumentaram os níveis de adição de $P$ (Figura 5). Este fato não ocorreu devido ao aumento das quantidades de $P$ adicionadas mas, provavelmente em função da diminuição das quantidades puras de lodo de esgoto alcalinizado nas misturas referentes aos maiores níveis de adição e a consequente redução no fornecimento de outros macro e micronutrientes nele presentes. Chueiri et al. (2007) ao contrário dos resultados verificados neste trabalho concluiram que 'lodo de esgoto alcalinizado afetou negativamente algumas características morfológicas do trigo e a produção de matéria seca enquanto o fertilizante exerceu efeito benéfico sobre os mesmos parâmetros, indicando que, apesar de adicionar nutrientes ao solo, o lodo de esgoto alcalinizado deverá ter sua aplicação controlada". Cabe aqui salientar que a dose máxima utilizada por estes autores (10 Mg $\mathrm{ha}^{-1}$ ) pode ser considerada de baixa a intermediária em relação às doses comumente utilizadas nas pesquisas atuais relacionadas à destinação final de lodos de esgoto alcalinizados no solo. Assim, a afecção negativa do lodo sobre as plantas pode-se dever à diminuição da disponibilidade de manganês no solo em função do aumento do $\mathrm{pH}$ ou a um provável efeito negativo condicionado à sua utilização num solo com as características químicas inicialmente observadas $(\mathrm{pH}=6,2$ e o relativamente bom estado de fertilidade). Alguns outros trabalhos aplicaram lodo de esgoto com complementação com fertilizante mineral fosfatado. Dentre eles está o de Nascimento et al. (2004) que misturaram doses crescentes de lodo de esgoto com Argissolo textura média e Espodossolo textura arenosa e, semelhantemente ao resultado em discussão, observaram concomitantes aumentos na produção de massa seca de milho e feijão, concluindo que a produção pode ser aumentada quando se suplementa lodo de esgoto com fertilizante fosfatado à dose de $400 \mathrm{mg} \mathrm{P} \mathrm{dm}^{-3}$ de solo, cerca de 17 vezes maior que a dose utilizada no presente trabalho $\left(23 \mathrm{mg} \mathrm{dm}^{-3}\right.$ ). No trabalho desenvolvido por Simonete et al. (2003) foram incubadas doses crescentes de lodo de esgoto de $\mathrm{P}$ e, em seguida, aplicaram 0 e $100 \mathrm{mg} \mathrm{kg}^{-1}$ (cerca de 4 vezes maior que a dose máxima de $P$ utilizada neste trabalho) ao solo tratado. Verificaram aumentos na produção de matéria seca da parte aérea de plantas de milho à medida que aumentaram as doses de lodo de esgoto. Este resultado foi análogo ao observado para a produção das plantas de feijoeiro no presente trabalho. Porém, não houve significância na interação entre as doses de lodo e a complementação mineral fosfatada por eles utilizada.

Numericamente, o tratamento referente ao nível $0,436 \% \mathrm{P}$ a partir de FPA e de $0,436 \%$ e $0,872 \% \mathrm{P}$ a partir do SS proporcionaram as maiores produções de massa seca, observando-se aumentos de até $37 \%$ para o nível $0,436 \% \mathrm{P}$ da primeira fonte e $0,872 \% \mathrm{P}$ da segunda fonte (Tabela 5). Bar-Tal et al. (2004) também observaram aumentos na produção de massa seca da cultura do trigo concomitantes aos aumentos de doses de lodo de esgoto utilizadas, cerca de 3, 6 e 12 vezes maiores que a dose máxima utilizada neste trabalho $\left(10 \mathrm{Mg} \mathrm{ha}^{-1}\right)$. Ressalte-se que os níveis $0,436 \% \mathrm{P}$ a partir destas fontes de adição também estiveram dentre os tratamentos que proporcionaram os maiores aumentos na produção de grãos. Foram verificadas correlações lineares positivas para a massa seca total produzida em função do teor de $P$ extraído do solo pelo extrator Mehlich-1 obtido a partir de níveis de adição com as fontes FPA e SS (Figura 6). O fato indica que a produção de massa seca aumenta proporcionalmente ao aumento do teor extraível de $\mathrm{P}$ do solo, o que não ocorreu para a fonte ST, que apresentou apenas fraca correlação. Estes resultados também são ratificados pela alta correlação linear positiva verificada para produção de grãos em função da produção de massa seca total da parte aérea de feijoeiro, inclusive para o ST (Figura 7). Ou seja, a quantidade de grãos produzida para cada fonte individual de adição de $P$ aumentou concomitantemente ao aumento da produção total de massa seca da parte aérea de feijoeiro. Resultados semelhantes foram registrados por Fageria et al. (2004). Tais resultados sugerem que o lodo de esgoto alcalinizado, ao exercer efeito positivo sobre as características químicas do solo, aumenta a disponibilidade de $\mathrm{P}$ para as plantas. Sendo assim, tanto quantidades pequenas quanto intermediárias ${ }^{5}$ destes biossólidos (cerca de $10 \mathrm{Mg}$ $\mathrm{ha}^{-1}$ ) podem ser misturadas com $\mathrm{P}$, proporcionando maiores absorção e acumulação de $P$ pelas plantas e, como consequência, uma maior produtividade da cultura do feijoeiro.

\footnotetext{
${ }^{5}$ Intermediária em relação às doses normalmente empregadas em pesquisas com lodos de esgoto. 
DA SILVA, L. C. et al. Lodo de esgoto alcalinizado adicionado de...

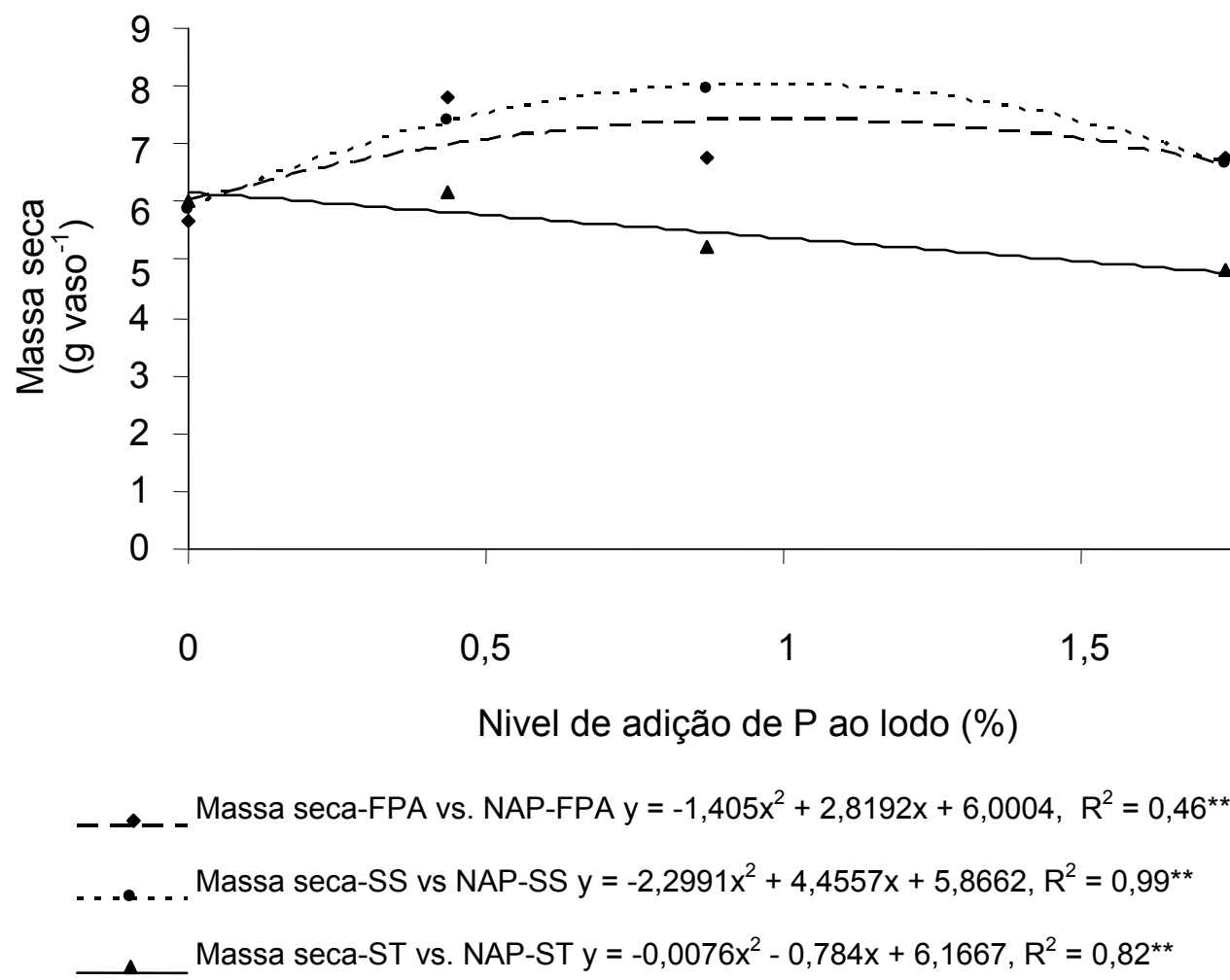

FIGURA 5 - Curvas de tendência de produção de massa seca total da parte aérea de feijoeiro em função do nível de adição de $\mathrm{P}$ a partir de fosfato natural parcialmente acidulado (Massa seca-FPA vs. NAPFPA), superfosfato simples (Massa seca-SS vs. NAP-SS) e superfosfato triplo (Massa seca-ST vs. NAP-ST) (F a $\mathrm{P}<0,01)$

TABELA 5 - Comparação de médias de produção de massa seca em função de fontes de adição de $\mathrm{P}$ em lodo de esgoto alcalinizado ( $\mathrm{F}$ a $\mathrm{P}<0,01)$

\begin{tabular}{|c|c|c|c|c|}
\hline \multicolumn{5}{|c|}{$\operatorname{NAP}^{1}(\%)$} \\
\hline $\mathrm{FAP}^{2}$ & 0 & 0,436 & 0,872 & 1,745 \\
\hline & ----. & -1-------N & $\left.\operatorname{aso}^{-1}\right)$ & -ב--- \\
\hline $\mathrm{FPA}^{3}$ & $5,690 \mathrm{a}$ & $7,790 \mathrm{a}$ & $6,770 \mathrm{a}$ & 6,745 a \\
\hline $\mathrm{SS}^{4}$ & $5,853 \mathrm{a}$ & $7,407 \mathrm{ab}$ & 7,977 a & $6,645 a$ \\
\hline $\mathrm{ST}^{5}$ & $6,033 \mathrm{a}$ & $6,188 \mathrm{~b}$ & $5,217 \mathrm{~b}$ & $4,825 \mathrm{~b}$ \\
\hline CV (\%) & 11,83 & & & \\
\hline DMS & 1,29 & & & \\
\hline
\end{tabular}

Médias seguidas de mesma letra na vertical não diferem estatisticamente pelo teste de Tukey ao nível de $95 \%$ de probabilidade.

${ }^{1} \mathrm{NAP}(\%)=$ nível de adição de lodo de esgoto alcalinizado com fósforo, em porcentagem; ${ }^{2} \mathrm{FAP}=$ fonte de adição de lodo de esgoto alcalinizado com fósforo; ${ }^{3}$ Fosfato natural parcialmente acidulado Alvorada; ${ }^{4}$ Superfosfato simples; ${ }^{5}$ Superfosfato triplo. 
DA SILVA, L. C. et al. Lodo de esgoto alcalinizado adicionado de ...

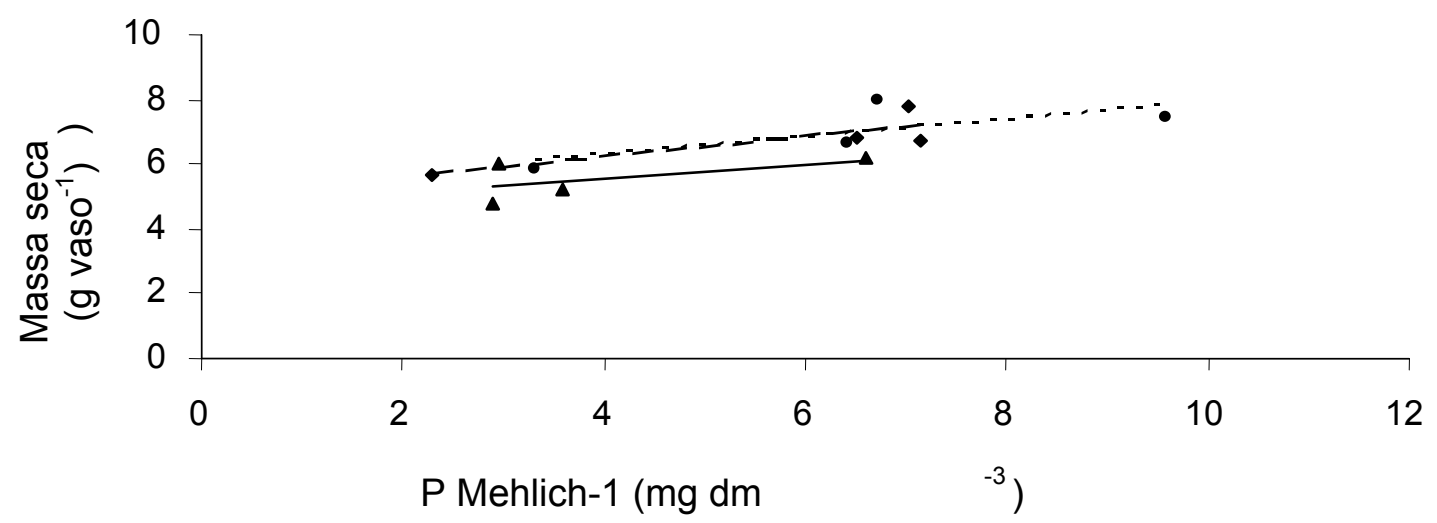

$\ldots \rightarrow$ Massa seca-FPA vs. P Mehlich-1-FPA y $=0,311 x+4,9627, R^{2}=0,70^{* *}$

.... . . Massa seca-SS vs. P Mehlich-1-SS $y=0,2609 x+5,2696, R^{2}=0,52^{* *}$

_._Massa seca-ST vs. P Mehlich-1-ST $y=0,2241 x+4,6614, R^{2}-0,36^{* *}$

FIGURA 6 - Curvas de tendência de produção de massa seca total da parte aérea de feijoeiro em função de $P$ extraível Mehlich-1 proporcionados pelo fosfato natural parcialmente acidulado Alvorada (Massa seca-FPA vs. P Mehlich-1-FPA), superfosfato simples (Massa seca-SS vs. P Mehlich-1-SS) e superfosfato triplo (Massa seca-ST vs. P Mehlich-1-ST) (F a $\mathrm{P}<0,01$ )
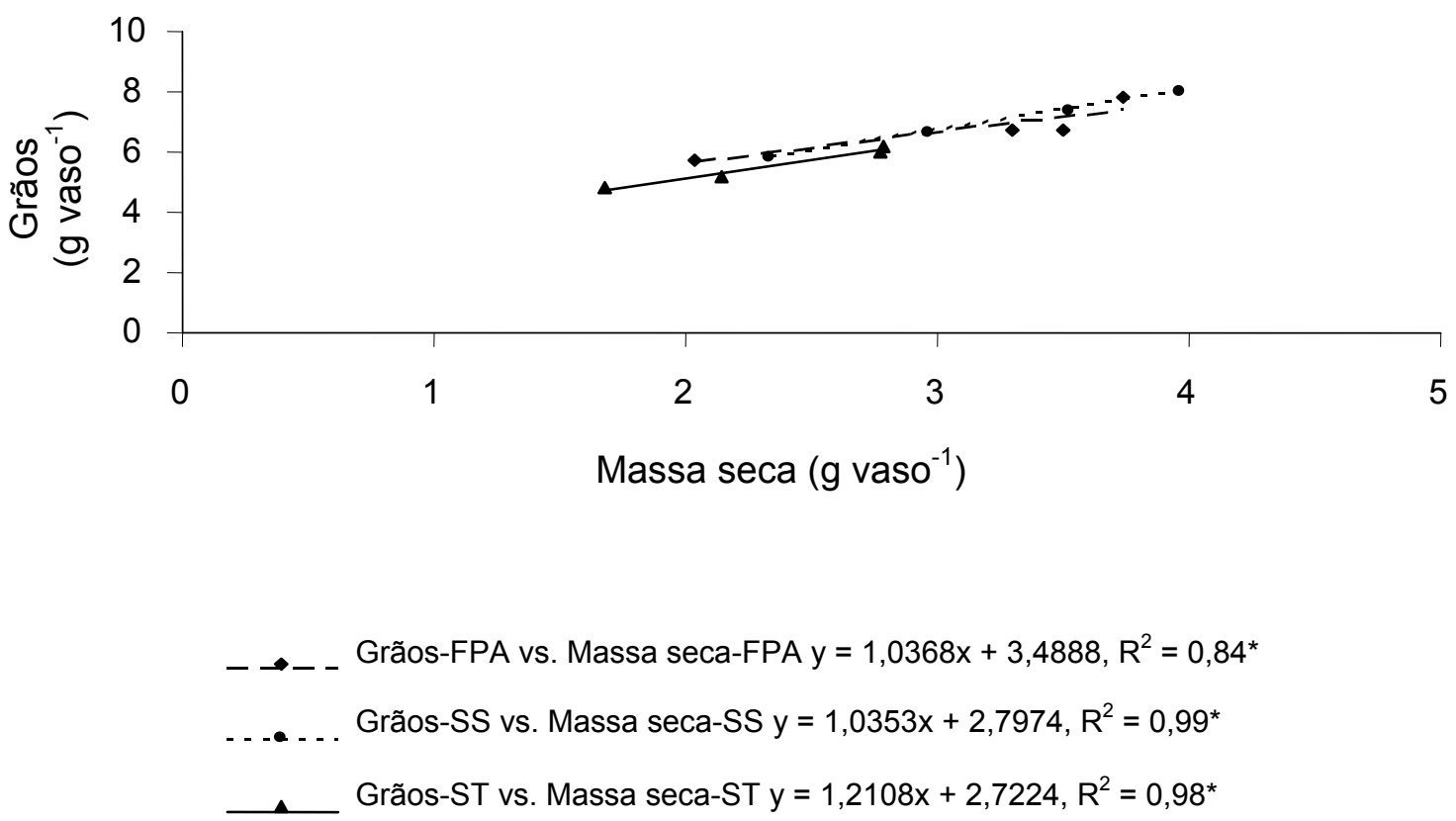

FIGURA 7 - Curvas de tendência de produção de grãos em função da produção de massa seca total da parte aérea de feijoeiro proporcionados pelo nível de adição de $\mathrm{P}$ em lodo de esgoto alcalinizado a partir de fosfato natural parcialmente acidulado Alvorada (Grãos-FPA vs. Massa seca-FPA), superfosfato simples (Grãos-SS vs. Massa seca-SS) e superfosfato triplo (Grãos-ST vs. Massa seca-ST) (F a $P<0,01)$ 
DA SILVA, L. C. et al. Lodo de esgoto alcalinizado adicionado de...

Aumento linear foi verificado para os índices de eficiência agronômica (IEA) em relação à produção de massa seca total da parte aérea de feijoeiro obtida com os níveis $0,436 \%, 0,872 \%$ e $1,745 \% \mathrm{P}$ a partir de FPA e SS (Figura 8). Entretanto, o fato não se deve a um aumento na produtividade de massa seca a partir dos níveis de adição com FPA e SS, mas sim, ao decréscimo na produtividade (Tabela 6 ) observado à medida que aumentaram os níveis de $\mathrm{P}$ a partir da fonte de referência (ST). Dessa forma, o nível de adição de $\mathrm{P}$ mais eficiente foi $0,436 \% \mathrm{P}\left(1 \% \mathrm{P}_{2} \mathrm{O}_{5}\right)$ a partir de ambas as fontes testadas uma vez que foram calculados com a maior produtividade proporcionada pelo ST. Numericamente, o FPA como fonte de adição de $\mathrm{P}$ proporcionou uma produção $25,85 \%$ maior em relação ao ST. Já o SS levou a uma produção $19,7 \%$ maior em relação ao mesmo nível de adição de $\mathrm{P}$ a partir da fonte de referência.

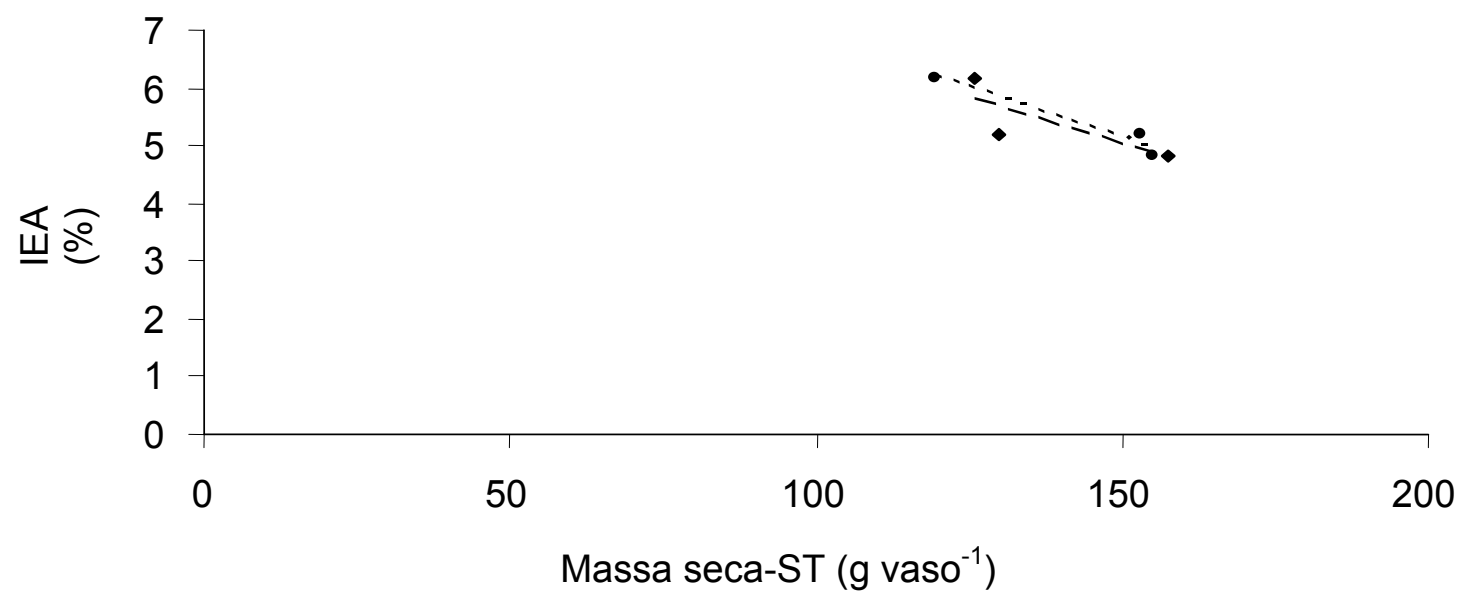

$\ldots \rightarrow-$ IEA-FPA(\%) vs. Massa seca-ST $\left(\right.$ g vaso $\left.^{-1}\right) y=-0,0323 x+9,8515, R^{2}=0,63^{\star *}$
$\ldots \ldots$. . IEA-SS $(\%)$ vs. Massa seca-ST $\left(\right.$ g vaso $\left.^{-1}\right) y=0,0344 x+10,312, R^{2}=0,94^{\star *}$

FIGURA 8 - Curvas de tendência de índices de eficiência agronômica do nível de adição de P em lodo de esgoto alcalinizado a partir de fosfato natural parcialmente acidulado Alvorada (IEA-FPA) e superfosfato simples (IEA-SS) em função da massa seca total da parte aérea de feijoeiro produzida pela fonte de adição de $\mathrm{P}$ utilizada como fonte referência superfosfato triplo (Massa seca-ST) (F a $\mathrm{P}<0,01)$

TABELA 6 - Índices de eficiência agronômica calculados a partir de dados de massa seca total da parte aérea de feijoeiro ( $\mathrm{F}$ a $\mathrm{P}<0,01)$

\begin{tabular}{|c|c|c|c|c|c|}
\hline $\mathrm{NAP}^{1}$ & MSTPA-ST ${ }^{2}$ & MSTPA-FPA ${ }^{3}$ & MSTPA-SS ${ }^{4}$ & IEA-FPA $^{5}$ & IEA-SS $^{6}$ \\
\hline$(\%)$ & 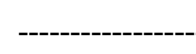 & $\left(\right.$ vaso $\left.^{-1}\right)$ & 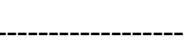 & $(\%)$ & $(\%)$ \\
\hline 0,436 & 6,180 & 7,790 & 7,407 & 125,800 & 119,700 \\
\hline 0,872 & 5,210 & 6,770 & 7,977 & 129,700 & 152,900 \\
\hline 1,745 & 4,280 & 6,740 & 6,640 & 157,400 & 155,000 \\
\hline
\end{tabular}

${ }^{1}$ NAP: nível de adição de $\mathrm{P}$ em lodo de esgoto alcalinizado, com excessão do nível $0 \% \mathrm{P} ;{ }^{2} \mathrm{MSTPA}-\mathrm{ST}=$ massa seca total da parte aérea de feijoeiro produzida a partir de níveis de adição de $\mathrm{P}$ com ST; ${ }^{3} \mathrm{MSTPA}-\mathrm{FPA}=$ massa seca total aérea de feijoeiro produzida com os níveis de enriquecimento a partir de FPA; ${ }^{4}$ MSTPA-SS = massa seca total da parte aérea de feijoeiro produzida com os melhores níveis de adição de P a partir de SS; ${ }^{5} \mathrm{IEA}-\mathrm{FPA}=$ Índice de eficiência agronômica de níveis de adição de $\mathrm{P}$ a lodo de esgoto alcalinizado a partir de FPA; ${ }^{6} \mathrm{IEA} / \mathrm{SS}$ = Índice de eficiência agronômica para os níveis de adição de $\mathrm{P}$ em lodo de esgoto alcalinizado a partir de FPA. 
DA SILVA, L. C. et al. Lodo de esgoto alcalinizado adicionado de ...

\section{CONCLUSÕES}

Sob as presentes condições experimentais: i) O melhor nível de fósforo adicionado em lodo de esgoto alcalinizado é $0,436 \%$ e; ii) Tanto o fosfato natural parcialmente acidulado Alvorada quanto o superfosfato simples podem ser utilizados em mistura com lodo de esgoto alcalinizado desde que considerado o melhor nível de fósforo adicionado.

\section{AGRADECIMENTOS}

À Universidade Federal do Paraná, pela oportunidade de aprendizado e à CAPES, pela concessão da bolsa de estudos.

\section{REFERÊNCIAS}

1. BAR-TAL, A.; YERMIYAHU, U.; BERAUD, J.; KEINAN, M.; ROSENBERG, D.; ZOHAR, D.; ROSEN, V.; FINE, P.; Nitrogen, phosphorus, and potassium uptake by wheat and their distribution in soil following successive, annual compost application.; Journal of Environmental Quality, v. 33, n. 5, p. 1855-1865, 2004.

2. CHIEN, S.H., SALE, P.W.G., FRIESEN, D.K. A discussion of the methods for comparing the relative effectiveness of phosphate fertilizers varying in solubility. Fertiliser Research, v. 24, n. 2, p. 149-157, 1990.

3. CHRISTIE, P.; EASSON, D.L.; PICTON, J.R.; LOVE, S.C.P. Agronomic value of alkaline-stabilized sewage biosolids for spring barley. Agronomy Journal, v. 93, n. 1, p. 144-151, 2001.

4. $\quad$ CHUEIRI, W.A.; SERRAT, B.M.; BIELE, J.; FAVARETTO, N.; Lodo de esgoto e fertilizante mineral sobre parâmetros do solo e de plantas de trigo; Revista Brasileira de Engenharia Agrícola e Ambiental, v. 11, n. 5, p. 502-508, 2007.

5. COMISSÃO DE QUÍMICA E FERTILIDADE DO SOLO - CQFS - SC/RS. Recomendações de adubação e calagem para os Estados do Rio Grande do Sul e Santa Catarina. Porto Alegre: Sociedade Brasileira de Ciência do Solo, Núcleo Regional Sul, 2004.

6. COMPANHIA DE SANEAMENTO DO PARANÁ - SANEPAR. Manual técnico para utilização agrícola do lodo de esgoto no Paraná. Curitiba, 1997. $96 \mathrm{p}$.

7. EMBRAPA. Centro Nacional de Pesquisa de Solos. Manual de métodos de análise de solo. 2. ed. Rio de Janeiro, 1997. 212 p.

8. FAGERIA, N.K.; BARBOSA FILHO, M.P.; STONE, L.F. Nutrição de fósforo na produção de feijoeiro. In: TSUIOSHI, Y.; STIPP, S.R.A. (Org.). Fósforo na agricultura brasileira. Piracicaba: Associação Brasileira para Pesquisa Potassa e Fosfato, 2004. p. 435-455.

9. FAGERIA. N. K. Eficiência de uso de fósforo pelos genótipos de feijão. Revista Brasileira de Engenharia Agrícola e Ambiental, v. 2, n. 2, p. 128-131, 1998.

10. LOGAN, T.J.; HARRISON, B.J. Physical characteristics of alkaline stabilized sewage sludge (N-Viro Soil) and their effects on soil physical properties. Journal of Environmental Quality, v. 24, n. 5, p. 153-164, 1995

11. LOURENÇO, R.S.; ANJOS, A.R.M.; MEDRADO, M.J.S. Efeito do lodo de esgoto na produtividade de milho e feijão no sistema de produção de bracatinga. Sanare, v. 5, p. 90-92, 1996.

12. MALAVOLTA, E. Manual de nutrição mineral de plantas. Piracicaba: Agronômica Ceres, 2006. 638 p.

13. MUÑOZ HERNANDEZ.; R.J.; SILVEIRA, R.I. Efeitos da saturação por bases, relações Ca:Mg no solo e níveis de fósforo sobre a produção de material seco e nutrição mineral do milho (zea mays, I.); Scientia Agrícola, v. 55, n. 1, p. 79-85, 1998

14. NASCIMENTO, C., W., A.; BARROS, D., A., S.; MELO, E., E., C.; OLIVEIRA, A., B. - Alterações químicas em solos e crescimento de milho e feijoeiro após aplicação de lodo de esgoto, Revista Brasileira de Ciência do Solo, v. $28, \mathrm{n}$. 2, p. 385-392, 2004

15. NOVAIS, R.F.; SMITH, T.J. Fósforo em solo e planta em condições tropicais. 1. ed. Viçosa: Ed. da UFV, 1999.

16. SILVA, F.C.; BOARETTO, A. E., BERTON, R. S. Efeito de lodo de esgoto na fertilidade de um argissolo vermelhoamarelo cultivado com cana de açúcar. Pesquisa Agropecuária Brasileira, v. 36, n. 5, p. 831-840, 2001.

17. SILVA, J.E.; RESCK, D.V.S.; SHARMA, R.D. Alternativa agronômica para o biossólido produzido no Distrito Federal. I - Efeito na produção de milho e adição de metais pesados em Latossolo no cerrado. Revista Brasileira de Ciência do Solo, v. 26, n. 3, p. 487-495, 2002.

18. SIMONETE, M.A.; KIEHL, J.C; ANDRADE, C.A.; TEIXEIRA, C.F.A.; Efeito do lodo de esgoto em um Argissolo e no crescimento e nutrição de milho; Pesquisa Agropecuária Brasileira, v. 38, n. 10, p. 1187-1195, 2003.

Recebido em 14/09/2009 Aceito em 07/10/2010 
